\title{
Influence of colonic mesenteric area on the number of lymph node retrieval for colon cancer: a prospective cohort study
}

\author{
Nadir Adnan Hacım ${ }^{1}$, Ahmet Akbaş ${ }^{1}$, Yigit Ulgen ${ }^{2}$, Talar Vartanoglu Aktokmakyan ${ }^{1}$, Serhat Meric ${ }^{1}$, \\ Merve Tokocin $^{1}$, Onder Karabay ${ }^{3}$, Yuksel Altinel ${ }^{1}$ \\ ${ }^{1}$ Department of General Surgery Bagcilar Training and Research Hospital, Istanbul, Turkey \\ ${ }^{2}$ Department of Pathology, Bagcilar Training and Research Hospital, Istanbul, Turkey \\ ${ }^{3}$ Department of Surgery, Yedikule Surp Pırgiç Armenian Hospital, Istanbul, Turkey
}

Purpose: The minimum harvested 12 lymph nodes (LNs) is regarded as the limit for accurate staging of nodal status in colorectal cancer patients. Besides the association of the lengths of resected intestinal segments and vascular pedicles, the mesocolic mesenteric area's impact on LN count has not been studied. We aimed to evaluate the associations between metric variables, including the mesocolic mesentery area on the nodal harvest.

Methods: All consecutive patients who underwent elective colectomy with a curative intention for colon adenocarcinoma were prospectively included. The metric variables included the lengths of resected intestinal segments, vascular pedicle, and colonic mesenteric area. The variables influencing the LN count and the correlation between the total LN count and the specimens' relevant metric measurements were analyzed.

Results: There were 46 patients with a median age of 64 years. The median count for total LNs was 22 , and the LN positivity was $59.2 \%$. There was an inadequate $\mathrm{LN}$ yield $(<12)$ in 3 patients $(6.1 \%)$. No significant associations were found between the adequacy of nodal harvest and the demographic, clinical, and tumoral features $(\mathrm{P}>0.05)$. There were significant positive correlations between total LN number and length of vascular pedicle and mesenteric area $(r=0.576, P<0.001$ and $\mathrm{r}=0.566, \mathrm{P}<0.001)$.

Conclusion: The length of the vascular pedicle and mesenteric area were significantly correlated with total LN counts. Although there was no significant impact on the length of resected segments, the colonic mesenteric area can be used alone as a measure for the assessment of the nodal yield in colon cancer.

Keywords: Colonic neoplasms; Lymph node dissection; Colectomy

\section{INTRODUCTION}

An acceptable minimum harvested lymph node (LN) count during surgical treatment of colon cancer has been advocated by

Received: Jun 5, 2021 - Revised: Jul 30, 2021 - Accepted: Jul 31, 2021 Correspondence to: Nadir Adnan Hacım, MD

Department of General Surgery, Bagcilar Training and Research Hospital,

Merkez Mah. Dr. Sadık Ahmet Cd. No: 5, Istanbul 34200, Turkey

Email:adnanhcm@hotmail.com

ORCID: https://orcid.org/0000-0002-3906-2538

(C) 2023 The Korean Society of Coloproctology

This is an open-access article distributed under the terms of the Creative Commons Attribution NonCommercial License (https://creativecommons.org/licenses/by-nc/4.0) which permits unrestricted non-

commercial use, distribution, and reproduction in any medium, provided the original work is properly cited. many national associations [1]. Besides being an indicator of surgical treatment quality, the minimum harvested 12 LNs is required for accurate staging of colorectal cancer patients [2-4]. Removal of adequate, even higher counts of LNs is shown to be associated with better survival specifically for right-sided colon cancer [5-7].

In previous studies, the association of several variables with the total LN count has been analyzed. Patients' general health, age, sex, operative, and tumoral features, including the length of resected bowel, mesocolic mesenteric area, tumor site, and tumor mass, would be essential parameters leading to the different outcomes of LNs yield $[3,8,9]$.

Although the length of resected colon is dependent on mucosal margins, arterial anatomic variations, and extent of lymphadenec- 
$\begin{array}{rr}\text { Annals of } & \begin{array}{l}\text { Influence of colonic mesen } \\ \text { a prospective cohort study }\end{array} \\ \text { Coloproctology Adnan Hacim, et al. }\end{array}$

tomy, resection of longer colonic segments with larger mesocolic mesentery may also lead to higher counts of LN [10]. An increase in the number of retrieved LNs with increasing length of resected colon segments has been shown $[3,8,11-17]$. The relationship between the length of the colon and the mesocolic mesenteric area associated with the LN count has not been studied in detail. The area's measurement may be an indirect representation of both the resected colon and the vascular pedicle's lengths. So, assessment of these associations may be essential parameters that necessitate any standardization measure. We hypothesized that there is a close association between the mesocolic mesenteric area and the number of harvested LNs leading to an adequate staging. But, the impact of harvesting more LNs on the staging of colon cancer remains controversial.

In this study, we aimed to evaluate the total LN count following colectomy and analyze the impact of metric variables, including the lengths of resected bowel, vascular pedicle, and the mesocolic mesenteric area on the nodal harvest.

\section{METHODS}

\section{Ethical statements}

This study was a prospective analysis of all patients with colon cancer surgery at the General Surgery Clinic of Bagcilar Education and Research Hospital in Istanbul, Turkey, between September 2019 and July 2020. The local Ethical Committee approved the study (No. 2020.12.1.11.198). The authors declared that they performed the study according to the Declaration of Helsinki. Written consent for publication of this study and accompanying images was taken from patients. The study was registered to www. clinicaltrials.gov with an ID number of NCT04260139.

\section{Patients and variables}

All consecutive patients who underwent colectomy with a curative intention for colon cancer were included. Each surgery was performed by 1 of 5 colorectal surgeons with at least 10 years of experience.

The inclusion criteria were as follows: patients over 18 years of age; histological diagnosis of colonic adenocarcinoma; elective surgery; the type of surgery, including right and left hemicolectomies and the sigmoid resection for colon cancer; open, laparoscopic, or converted surgeries.

Previous colon surgery, emergent surgery, colectomy extending below the peritoneal reflection, total or subtotal colectomy, colectomy for other malignant and benign pathologies, and metastatic patients were regarded as the exclusion criteria.
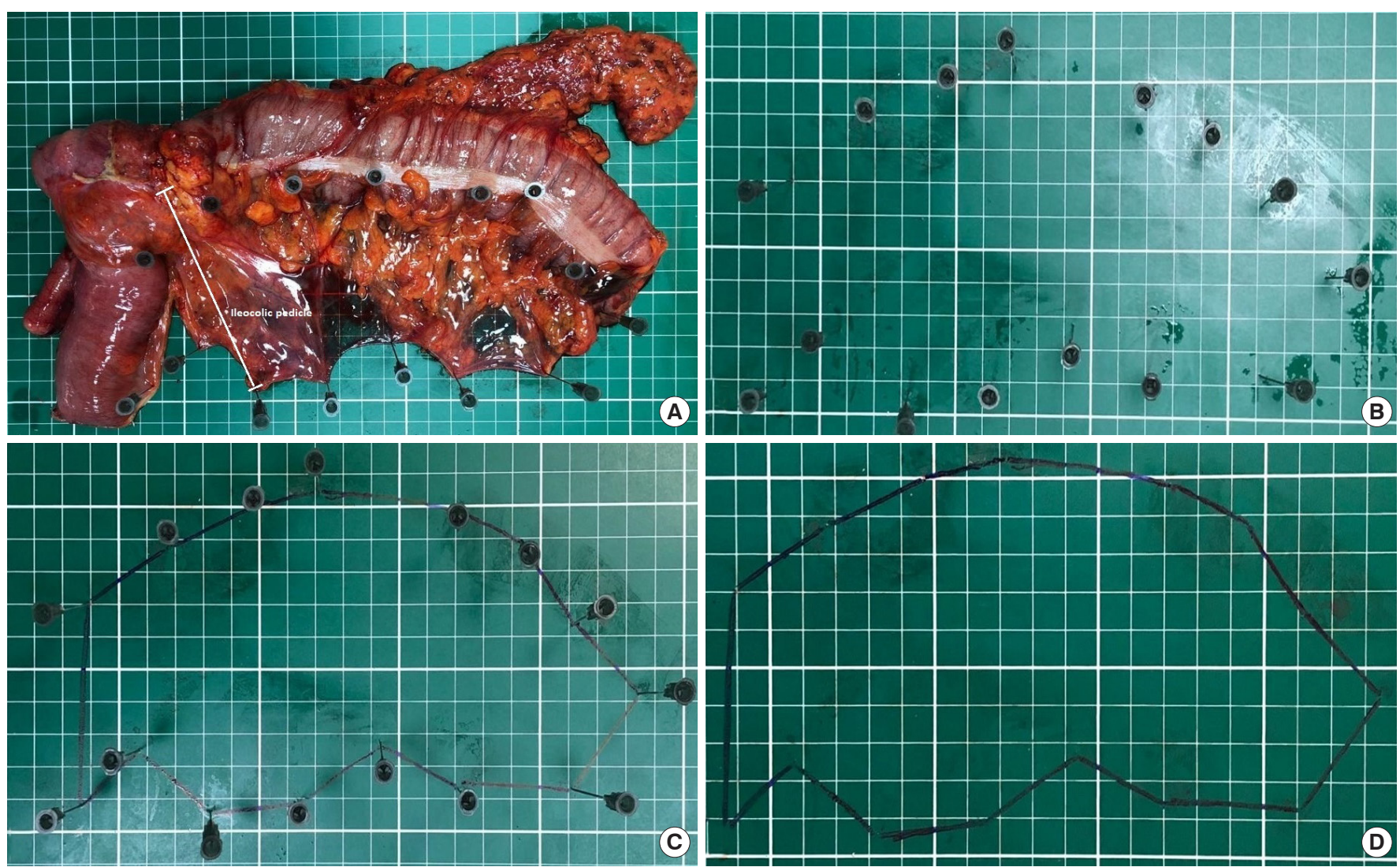

Fig. 1. Calculation of the colonic mesenteric area in the right hemicolectomy specimen on an engineering graph millimeter paper (from A to D). 
Volume 39, Number 1, 2023

Demographic and clinical characteristics were prospectively collected and recorded into a database. Age, sex, body mass index (BMI), surgical approach, type of operation, and tumoral features, including diameter, location, $\mathrm{T}$ and $\mathrm{N}$ stages, differentiation grade, and LN counts were recorded. The age of the patients was grouped as $<65$ and $\geq 65$ years $[1,15]$. The diameter of the tumor was stratified as $\leq 40$ and $>40 \mathrm{~mm}$ [15].

\section{Pathology}

After the incision's closure, the primary researcher (NAH) measured the distances given below and the colonic mesentery. The fresh specimen was fixed and laid out flat on an engineering graph millimeter paper in the operating room (Fig. 1A).

The lengths as millimeters are as follows: (a) proximal colon; (b) ileum in cases with right hemicolectomy only; (c) proximal border $(a+b$ in cases with the right hemicolectomy, only an in patients with other types of surgery); (d) tumor; (e) distal border; (f) total specimen $(\mathrm{c}+\mathrm{d}+\mathrm{e})$; $(\mathrm{g})$ vascular pedicle, the longitudinal distance between the nearest bowel wall and the end of ligated major vascular pedicle depending on the tumor's localization [1] (Fig. 2). The colonic mesenteric areas as $\mathrm{mm}^{2}$ are shown in Fig. $1 \mathrm{~B}-\mathrm{D}$.

The specimens were then directly sent to the pathology laboratory and examined in a standardized manner with manual dissection for the LNs. A consultant histopathologist performed microscopic and macroscopic pathological analysis using a standard

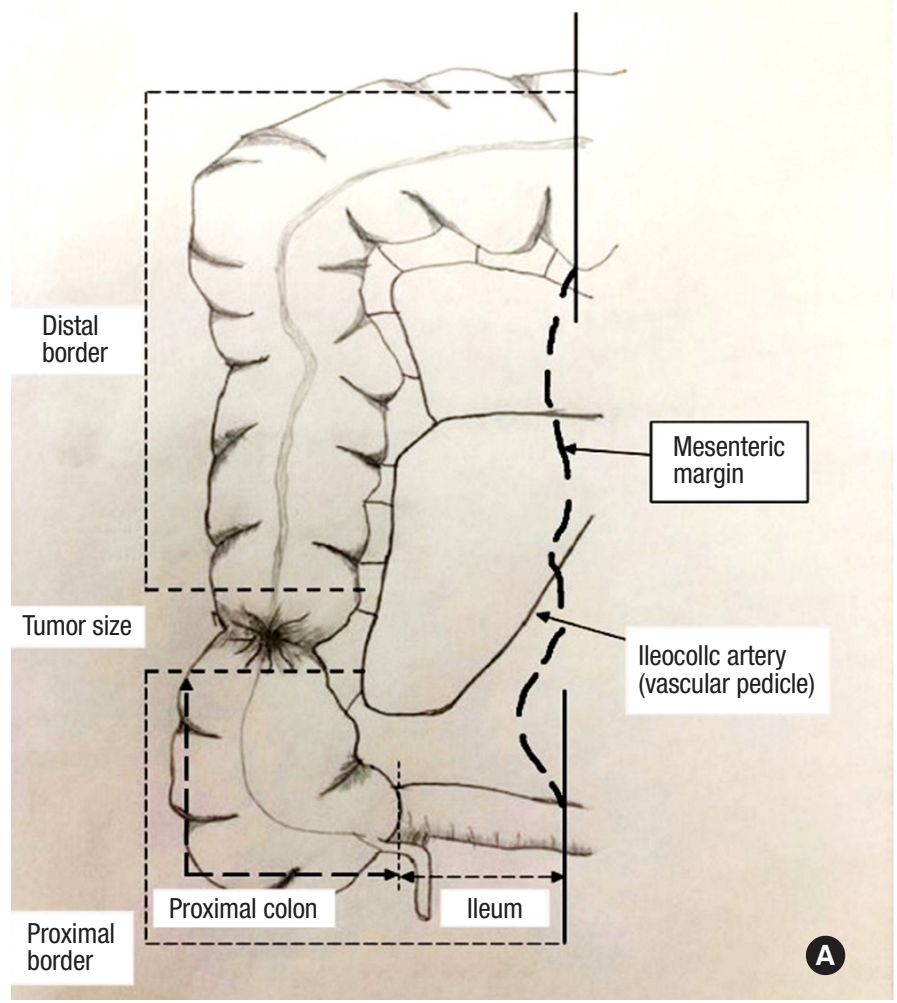

colorectal protocol. Fat-clearing methods were not used in each. In the case of the yield $<12 \mathrm{LNs}$, a second attempt to examine LNs was performed. The depth of invasion and the count of metastatic LNs supported the disease's stage using the TNM classification of the American Joint Committee on Cancer/Union for International Cancer Control, 7th edition [16].

The patients were divided into 2 groups according to the total count of LNs as $<12$ and $\geq 12[1]$.

\section{Statistical analysis}

The incidence of patients with a total count of $<12$ LNs and the association of the variables on this count were the primary outcomes. The correlation between the total LN count and the specimens' relevant metric measurements was regarded as the secondary outcome.

Descriptive statistics were given as mean \pm standard deviation and median with interquartile ranges (IQR) of $25 \%$ to $75 \%$ (IQR1-IQR3) for continuous variables depending on their distribution. Numbers and percentages were used for categorical variables. Normality of the numerical variables was analyzed by the Kolmogorov-Smirnov test and checked by Q-Q plots and histograms.

In comparing 2 independent groups, the t-test and one-way analysis of variance were used to compare the continuous variables with the normal distribution. For variables without normal

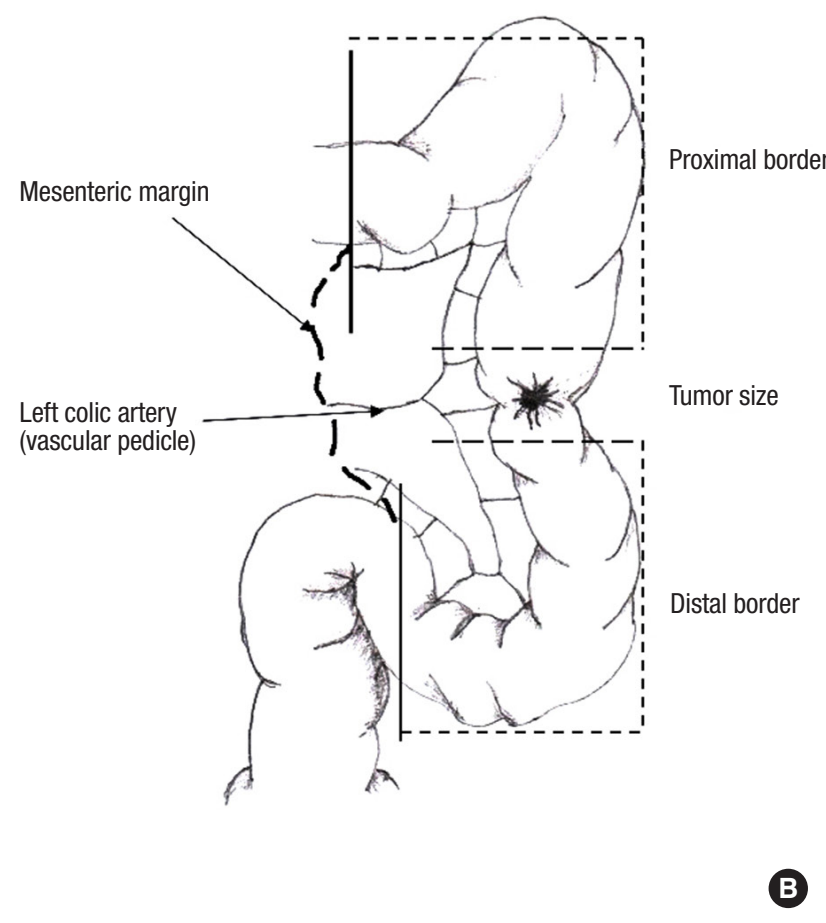

Fig. 2. Schematic representation of the metric variables on the right hemicolectomy (A) and the left hemicolectomy specimens (B). 
distribution, the Mann-Whitney U-test was applied. The Pearson chi-square test and Fisher exact tests were used for categorical variables. Spearman or Pearson correlation coefficient was used to analyze the associations between numerical variables. Statistical analysis was performed using an SPSS ver. 15.0 (SPSS Inc). A Pvalue of $<0.05$ was considered statistically significant.

\section{RESULTS}

There were 49 patients with a median age of 64 years. There were more male patients (53.1\%) in the study group. The laparoscopic approach (65.3\%) was more common than the open approach (20.4\%). Right hemicolectomy was performed in 22 patients (44.9\%), whereas in $20(40.8 \%)$ and 7 patients (14.3\%), sigmoid resection and left hemicolectomy were applied. The demographic and clinical characteristics of the patients are given in Table 1.

The median diameter of the tumors was $60 \mathrm{~mm}$. The sigmoid colon was the most common location seen in 20 patients (40.8\%). Considering T stages, $\mathrm{T} 3$ and $\mathrm{T} 4$ comprised the majority of the cases $(91.8 \%)$. Tumoral features of the study group are summarized in Table 2.

In the study group, the median count for total LNs was 22, and $59.2 \%$ of the patients were LN positive. In 3 patients (6.1\%), there was an inadequate $\mathrm{LN}$ yield $(<12)$. In these patients, the median total $\mathrm{LN}$ count was $8(\mathrm{P}<0.001)$ (Table 3$)$.

Table 1. Demographic and clinical characteristics of the patients

\begin{tabular}{lcccc}
\hline Variable & Overall & $\begin{array}{c}\text { Patients } \\
\text { with } \\
<12 \text { LNs }\end{array}$ & $\begin{array}{c}\text { Patients } \\
\text { with } \\
\geq 12 \text { LNs }\end{array}$ & P-value \\
\hline No. of patients & 49 & 3 & 46 & \\
Age (yr) & $64(55-77)$ & $75(53-80)$ & $64(55-77)$ & 0.671 \\
$<65$ & $27(55.1)$ & $1(33.3)$ & $26(56.5)$ & 0.581 \\
$\geq 65$ & $22(44.9)$ & $2(66.7)$ & $20(43.5)$ & \\
Sex & & & & $>0.999$ \\
$\quad$ Female & $23(46.9)$ & $1(33.3)$ & $22(47.8)$ & \\
$\quad$ Male & $26(53.1)$ & $2(66.7)$ & $24(52.2)$ & \\
Body mass index (kg/m²) & $27.8 \pm 13.5$ & $25.8 \pm 4.7$ & $27.9 \pm 5.5$ & 0.520 \\
Surgical approach & & & & 0.428 \\
$\quad$ Open & $10(20.4)$ & $0(0)$ & $10(21.7)$ & \\
Laparoscopic & $32(65.3)$ & $3(100)$ & $29(63.0)$ & \\
$\quad$ Converted & $7(14.3)$ & $0(0)$ & $7(15.2)$ & \\
Operation & & & & 0.622 \\
Right hemicolectomy & $22(44.9)$ & $1(33.3)$ & $21(45.7)$ & \\
Left hemicolectomy & $7(14.3)$ & $1(33.3)$ & $6(13.0)$ & \\
Sigmoid resection & $20(40.8)$ & $1(33.3)$ & $19(41.3)$ & \\
\hline
\end{tabular}

Values are presented as number only, median (interquartile range), number (\%), or mean \pm standard deviation.

LN, lymph node.
Table 2. Tumoral features of the study groups

\begin{tabular}{|c|c|c|c|c|}
\hline Variable & $\begin{array}{l}\text { Overall } \\
(n=49)\end{array}$ & $\begin{array}{l}\text { Patients } \\
\text { with } \\
<12 \text { LNs } \\
(n=3)\end{array}$ & $\begin{array}{l}\text { Patients } \\
\quad \text { with } \\
\geq 12 \text { LNs } \\
(n=46)\end{array}$ & $\mathrm{P}$-value \\
\hline Diameter (mm) & $60.0(50.0-75.0)$ & $70(50-90)$ & $60(50-70)$ & 0.560 \\
\hline$\leq 40$ & $7(14.3)$ & $0(0)$ & $7(15.2)$ & $>0.999$ \\
\hline$>40$ & $42(85.7)$ & $3(100)$ & 39 (84.8) & \\
\hline \multicolumn{5}{|l|}{ Location } \\
\hline Cecum & $4(8.2)$ & $0(0)$ & $4(8.7)$ & 0.798 \\
\hline Ascending & $16(32.7)$ & $1(33.3)$ & 15 (32.6) & \\
\hline Transverse & $3(6.1)$ & $0(0)$ & $3(6.5)$ & \\
\hline Descending & $6(12.2)$ & $1(33.3)$ & $5(10.9)$ & \\
\hline Sigmoid & $20(40.8)$ & $1(33.3)$ & $19(41.3)$ & \\
\hline \multicolumn{5}{|l|}{ T stage } \\
\hline 2 & $4(8.2)$ & $0(0)$ & $4(8.7)$ & 0.656 \\
\hline 3 & $21(42.9)$ & $2(66.7)$ & $19(41.3)$ & \\
\hline 4 & $24(49.0)$ & $1(33.3)$ & $23(50.0)$ & \\
\hline \multicolumn{5}{|l|}{ T group } \\
\hline T1-2 & $4(8.2)$ & $0(0)$ & $7(15.2)$ & $>0.999$ \\
\hline T3-4 & 45 (91.8) & $3(100)$ & 39 (84.8) & \\
\hline \multicolumn{5}{|l|}{ N stage } \\
\hline 0 & $20(40.8)$ & $1(33.3)$ & $19(41.3)$ & 0.364 \\
\hline 1 & $16(32.7)$ & $2(66.7)$ & $14(30.4)$ & \\
\hline 2 & $13(26.5)$ & $0(0)$ & $13(28.3)$ & \\
\hline \multicolumn{5}{|l|}{$\mathrm{N}$ group } \\
\hline NO & $20(40.8)$ & $1(33.3)$ & $19(41.3)$ & $>0.999$ \\
\hline N1-2 & 29 (59.2) & $2(66.7)$ & $27(58.7)$ & \\
\hline \multicolumn{5}{|l|}{ TNM stage } \\
\hline I & $2(4.1)$ & $0(0)$ & $2(4.3)$ & 0.592 \\
\hline Ila & $9(18.4)$ & $1(33.3)$ & $8(17.4)$ & \\
\hline$\| \mathrm{lb}$ & $9(18.4)$ & $0(0)$ & $9(19.6)$ & \\
\hline Illa & $2(4.1)$ & $0(0)$ & $2(4.3)$ & \\
\hline$\| l l b$ & $14(28.6)$ & $2(66.7)$ & 12 (26.1) & \\
\hline IIIC & $13(26.5)$ & $0(0)$ & $13(28.3)$ & \\
\hline \multicolumn{5}{|l|}{ Differentiation } \\
\hline Well & $6(12.2)$ & $0(0)$ & $6(13.0)$ & 0.794 \\
\hline Moderate & 30 (61.2) & $2(66.7)$ & $28(60.9)$ & \\
\hline Poor & $13(26.5)$ & $1(33.3)$ & $12(26.1)$ & \\
\hline Signet ring cell & $5(10.2)$ & $1(33.3)$ & $4(8.7)$ & 0.281 \\
\hline Mucinous pathology & $24(49.0)$ & $1(33.3)$ & $23(50.0)$ & $>0.999$ \\
\hline Lymphovascular invasion & $30(61.2)$ & $2(66.7)$ & $28(60.9)$ & $>0.999$ \\
\hline Perineural invasion & $22(44.9)$ & $2(66.7)$ & $20(43.5)$ & 0.581 \\
\hline
\end{tabular}

Values are presented as median (interquartile range) or number (\%).

$\mathrm{LN}$, lymph node. 
Table 3. Analysis of the morphometric features of the specimens with the groups based on total LN count

\begin{tabular}{|c|c|c|c|c|}
\hline Variable & Overall $(n=49)$ & Patients with $<12$ LNs $(n=3)$ & Patients with $\geq 12$ LNs $(n=46)$ & P-value \\
\hline Diameter (mm) & $60.0(50-75)$ & $70.0(50-90)$ & $60.0(50-70)$ & 0.560 \\
\hline Total LN & $22.0(14-32)$ & $8.0(6-10)$ & $23.0(16-32)$ & $<0.001$ \\
\hline Malignant LN & $1.0(0-4)$ & $1.0(0-1)$ & $1.0(0-4)$ & 0.758 \\
\hline Malignant-to-total LN & $0.32(0-0.13)$ & $0.13(0-0.2)$ & $0.03(0-0.13)$ & 0.671 \\
\hline Specimen length (mm) & $310.0(242.5-405)$ & $310.0(245-460)$ & $315.0(240-410)$ & 0.939 \\
\hline Tumor length (mm) & $35.0(27.5-45)$ & $30.0(15-30)$ & $40.0(30-50)$ & 0.116 \\
\hline Proximal border (mm) & $180.0(80-307.5)$ & $240.0(170-390)$ & $180.0(80-305)$ & 0.323 \\
\hline Distal border (mm) & $120.0(80-190)$ & $80.0(40-110)$ & $130.0(80-200)$ & 0.088 \\
\hline Proximal colon length (mm) & $90.0(60-150)$ & $280.0(170-390)$ & $80.0(60-145)$ & 0.051 \\
\hline lleum length (mm) & $115.9 \pm 43.0$ & 90 & $117.1 \pm 43.6$ & 0.635 \\
\hline Vascular pedicle length (mm) & $103.0 \pm 25.4$ & $88.7 \pm 14$ & $104.0 \pm 25.8$ & 0.317 \\
\hline Mesenteric area $\left(\mathrm{mm}^{2}\right)$ & $13,800(10,300-19,150)$ & $10,300(7,100-11,500)$ & $15,400(10,300-19,400)$ & 0.097 \\
\hline
\end{tabular}

Values are presented as median (interquartile range) or mean \pm standard deviation.

LN, lymph node.

Table 4. Correlation analysis of the total lymph node counts with morphometric tumoral features

\begin{tabular}{lcc}
\hline Variable & Spearman's rho & P-value \\
\hline Diameter & 0.176 & 0.226 \\
Specimen length & 0.117 & 0.423 \\
Tumor length & 0.112 & 0.442 \\
Proximal border & 0.215 & 0.138 \\
Distal border & 0.038 & 0.795 \\
Proximal colon length & 0.090 & 0.657 \\
lleal length & 0.171 & 0.447 \\
Vascular pedicle length & 0.576 & $<0.001$ \\
Mesenteric area & 0.566 & $<0.001$ \\
Malignant lymph node & -0.003 & 0.982 \\
Malignant-to-total lymph node & -0.155 & 0.287 \\
\hline
\end{tabular}

The patients with $<12$ and $\geq 12$ LNs have had similar demographic, clinical, and tumoral features. No significant associations were found between the adequacy of LN retrieval and the variables $(\mathrm{P}>0.05)$ (Tables 1, 2).

Although there was a significant difference in the total LN count in patients with $<12 \mathrm{LNs}$ and $\geq 12 \mathrm{LNs}(\mathrm{P}<0.001)$, we did not found a significant difference in malignant LNs between the groups $(\mathrm{P}=0.758)$. Similarly, the malignant-to-total ratio was similar in the groups $(\mathrm{P}=0.671)$.

When comparing the patients with adequate vs. inadequate retrievals, the morphometric measures, including the lengths of specimen, tumor, proximal border, distal border, and vascular pedicle, were also similar in the groups $(\mathrm{P}>0.05)$ (Table 3$)$. The ileum length in patients with right hemicolectomy and proximal colon length in patients with sigmoid resection and left hemicolectomy did not significantly differ between the groups $(\mathrm{P}>0.05)$. There was a longer length of the vascular pedicle and larger mesenteric area in patients with $\geq 12 \mathrm{LNs}$; we did not detect a statistical significance $(\mathrm{P}=0.317$ and $\mathrm{P}=0.097)$ (Table 3$)$.

Correlation analysis revealed that there were significant positive correlations between total LN count and the length of vascular pedicle and mesenteric area $(r=0.576, P<0.001$ and $r=0.566$, $\mathrm{P}<0.001$ ) (Table 4; Fig. 3A, B). However, there were no significant correlations between total LN count and other morphometric measurements. The morphometric measurements also did not correlate with the malignant LN count and $(\mathrm{P}>0.05)$ (Table 5).

\section{DISCUSSION}

This study showed significant correlations between total LN count and the length of vascular pedicle and mesenteric area. Although the grouping based on the minimum harvested 12 LNs for accurate staging of nodal status revealed no difference considering the length of the vascular pedicle and mesenteric area, we think that any increase in these 2 parameters may consequently lead to an increase in the probability of an accurate staging for colon cancer.

The LN yield in colon resection specimens is thought to be dependent on several variables. Although some are uncontrollable, including tumoral features, others are within the surgeons' control [1]. The length of vascular pedicle is another parameter that has an impact on the LN yield. It is expected to reach a similar length of vascular pedicles after the successful application of standardized techniques such as complete mesocolic excision and central vascular ligation. However, the length of the vascular pedicles may have different measurements due to the individual variations 

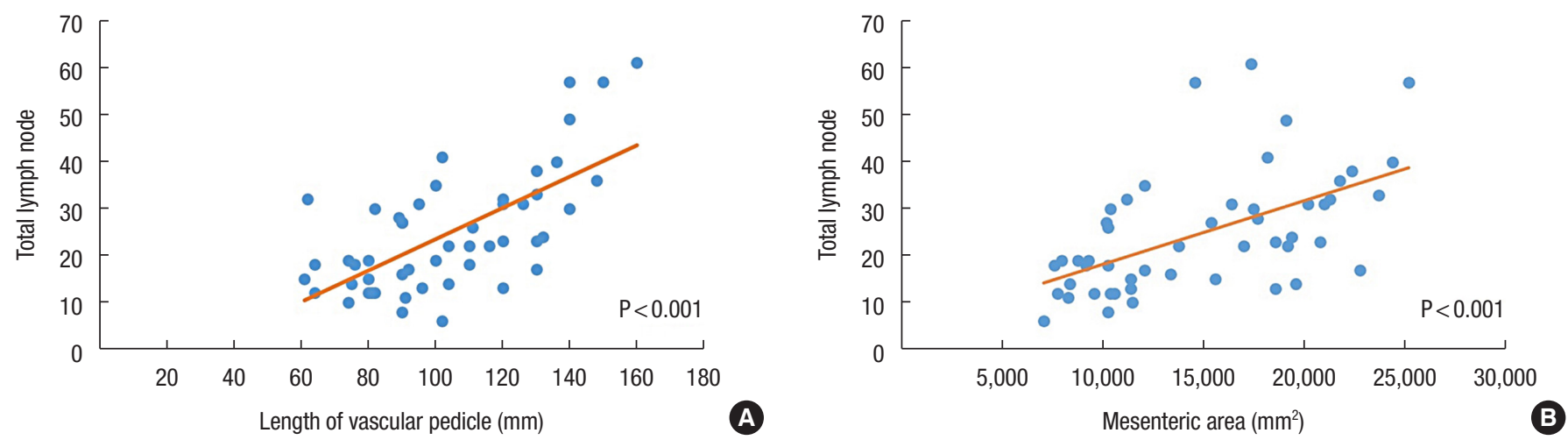

Fig. 3. Correlation of the total lymph node number with the length of vascular pedicle (A) and the colonic mesenteric area (B).

Table 5. Correlation analysis of malignant lymph node counts with morphometric tumoral features

\begin{tabular}{lcc}
\hline Variable & Spearman's rho & P-value \\
\hline Diameter & 0.176 & 0.226 \\
Specimen length & 0.062 & 0.674 \\
Tumor length & 0.062 & 0.673 \\
Proximal border & -0.020 & 0.891 \\
Distal border & 0.112 & 0.445 \\
Pedicle length & 0.163 & 0.262 \\
Mesentery area & 0.005 & 0.975 \\
\hline
\end{tabular}

associated with the body morphometric characteristics. Brändstedt et al. [18] showed that increasing quartiles of weight, hip, waist, BMI, and waist-hip ratio were significantly associated with an increased risk of $\mathrm{LN}$ positivity in men. But, they did not evaluate the possible relationship between the total $\mathrm{LN}$ count and the length of the vascular pedicles in patients with different body morphometric characteristics. In the current study, we could not evaluate such parameters except for BMI due to the retrospective design of the study. We also found no impact of BMI on the LN counts. It is recommended to take these parameters into consideration for future studies.

Kent et al. [8] showed that the pathological pedicle length correlated with the total nodal yield consistent with our results. In our study, longer length of the vascular pedicle and larger mesenteric area were found in patients with $\geq 12$ LNs without statistical significance. However, other numerical variables did not significantly associate with total LN yield. Based on these findings, we may think that the pedicle length is crucial in $\mathrm{LN}$ yield.

Besides the number of vascular pedicles in colon cancer surgery, the area of mesenteric resection, the length of vascular pedicle, and resected bowel are other variables predicting the LN count following colectomy [1]. All these parameters, separately or in combination, have been evaluated considering their impacts on the LN yield. Quality of the pathological examination is another essential parameter that has an impact on the number of retrieved LNs [19-21]. In the presence of adequate proximal and distal borders, a detailed and careful pathological examination may lead to an increased yield. Although the second-look LN search caused considerable increases in the LN counts and number of cases with at least $12 \mathrm{LNs}$, its benefit on the accurate staging was limited [20]. Becerra et al. [19] reported a large variation particularly between pathologists in suboptimal LN examination following colectomy. In the light of these explanations, we think that there is a difficulty in the standardization of the pathological examination techniques. Future studies are needed to investigate the impact of several approaches including the second-look LN search, exhaustive submission of mesenteric fat, or fat-clearing methods [20].

Although there were controversial results concerning the association of the length of resected bowel and the LN yield $[1,3,10,11$, $14,15]$, some authors also tried to find the cutoff values of specimen lengths for adequate LN counts. They showed that there should be almost $<20 \mathrm{~cm}$ of specimen length for sufficient $\mathrm{LN}$ counts [22, 23]. They evaluated both colon and rectal cancers in their study that can be regarded as a confounding factor. Others concluded that an increased resected mesenteric area is not associated with an increase in nodal yield, considering the lack of association with the total length of bowel resected and the total nodal yield [8]. In this study, we found a significant correlation between the mesenteric area and the total LN yield. If we regarded the mesenteric area as the reflection of both the length of vascular pedicle and resected intestinal segments, there should be little surprise that a higher yield of LNs would be achieved with resection of more mesenteric area. So, instead of the measurements of both the lengths of the vascular pedicle and the resected intestinal segments, the colonic mesenteric area may be used as a surrogate measure of surgical quality and nodal yield.

It is also logical to find that the number of the resected vascular pedicles may positively affect the total yield of LNs. However, Nash et al. [1] found that the mean number of nodes decreased as the degree of the pedicles increased from the primary to the tertiary. They detected the highest counts of LNs (14.6 LNs) for the 
primary pedicle and the lowest counts (3.6 LNs) for the tertiary pedicle. They thought that dissection of the vascular pedicle closest to the tumor caused this outcome. Lack of the measurements of the lengths may be regarded as a significant limitation for these results. In the present study, we did not differentiate the LNs found in the secondary or tertiary pedicles. However, the detection of the majority of LNs in the primary vascular pedicle as in Nash et al.'s study [1] supported our approach. Analysis of at least one major vascular pedicle can be regarded as sufficient for the nodal harvest.

Several patient-related and tumor-related factors have been identified as the significant independent risk factors for LN yield $[4,12,15]$. The right-sided tumors and larger tumor size were significantly associated with a higher total LN count $[1,12,14]$. There may be anatomic or biological differences between rightsided or left-sided colonic cancers. The authors speculated that increased cancer antigen presentation or inflammatory responses secondary to ulceration in larger tumors might result in such findings [15]. A longer mesenteric radix has also been questioned for right-sided tumors [14]. We believe that it is tough to understand the pathophysiological mechanisms for these associations. We also did not find any significant associations between tumoral features, including tumor size and location, and the LN groupings based on 12 LNs. Further prospective studies in which several predictors and confounder factors are considered are needed to address these questions.

In current studies, the rate of resections with adequate harvested LNs ranges up to $96.6 \%$ [1]. Our rate was $93.9 \%$. We may think that the infrequency of finding fewer than 12 LNs is so small to identify the predictive factors on the quality of LN dissection using a meaningful statistical analysis [1].

As an interesting finding, we did not find a significant correlation between the total and malignant LN in resected specimens. The absence of this correlation was also reported by other researchers $[1,3,14]$. Besides, there is a lack of data regarding improved survival secondary to the higher yield of total LNs in association with the mere elongation of the bowel resected [3]. Some studies also failed to show any improvement in the staging in association with an increased LN count $[5,20]$. So, evidences that an adequate number of nodes will alter the staging and improve outcomes should be provided by future studies.

The relatively low sample size of the study that can be regarded as insufficient to determine minor differences is the major limitation. Besides, the results of a single-center study may prevent the generalizability of the conclusions. The retrospective design and absence of survival outcomes were the other limitations. The measurement of the mesenteric area and the length of vascular pedicle were the study's main strengths.

In conclusion, the length of the vascular pedicle and mesenteric area was significantly correlated with total LN counts and, consequently, LN retrieval's adequacy following colon cancer surgery. The colonic mesenteric area can be used alone as a measure for the assessment of the nodal yield. Further studies are needed to evaluate the clinical use of such measurements in association with staging and survival.

\section{CONFLICT OF INTEREST}

No potential conflict of interest relevant to this article was reported.

\section{FUNDING}

None.

\section{REFERENCES}

1. Nash GM, Row D, Weiss A, Shia J, Guillem JG, Paty PB, et al. A predictive model for lymph node yield in colon cancer resection specimens. Ann Surg 2011;253:318-22.

2. Rajput A, Romanus D, Weiser MR, ter Veer A, Niland J, Wilson J, et al. Meeting the 12 lymph node (LN) benchmark in colon cancer. J Surg Oncol 2010;102:3-9.

3. Gravante G, Parker R, Elshaer M, Mogekwu AC, Humayun N, Thomas K, et al. Lymph node retrieval for colorectal cancer: estimation of the minimum resection length to achieve at least 12 lymph nodes for the pathological analysis. Int J Surg 2016;25:1537.

4. Norwood MG, Sutton AJ, West K, Sharpe DP, Hemingway D, Kelly MJ. Lymph node retrieval in colorectal cancer resection specimens: national standards are achievable, and low numbers are associated with reduced survival. Colorectal Dis 2010;12:3049.

5. Budde CN, Tsikitis VL, Deveney KE, Diggs BS, Lu KC, Herzig DO. Increasing the number of lymph nodes examined after colectomy does not improve colon cancer staging. J Am Coll Surg 2014;218:1004-11.

6. Mangone L, Pinto C, Mancuso P, Ottone M, Bisceglia I, Chiaran$\mathrm{da} \mathrm{G}$, et al. Colon cancer survival differs from right side to left side and lymph node harvest number matter. BMC Public Health 2021;21:906.

7. Rivadulla-Serrano MI, Martínez-Ramos D, Armengol-Carrasco M, Escrig-Sos J, Paiva-Coronel GA, Fortea-Sanchís C, et al. Impact of the total number of harvested lymph nodes after colon cancer resections on survival in patients without involved lymph node. Rev Esp Enferm Dig 2010;102:296-301.

8. Kent I, Rudnicki Y, Abu-Ghanem Y, White I, Spitz B, Avital S. Mesenteric root dissection with individualized ileo-colic vessel ligation versus mesenteric pedicle stapling. Surg Endosc 2016;30: 3021-5.

9. West NP, Hohenberger W, Weber K, Perrakis A, Finan PJ, Quirke P. Complete mesocolic excision with central vascular ligation produces an oncologically superior specimen compared with standard surgery for carcinoma of the colon. J Clin Oncol 2010; 


\section{8:272-8.}

10. Siebert M, Trilling B, Lamotte A, Taton N, Bellier A, Faucheron JL. Similar length of colon is removed regardless of localization in right-sided colonic cancer surgery. ANZ J Surg 2018;88:E568-72.

11. Conti C, Pedrazzani C, Turri G, Fernandes E, Lazzarini E, De Luca R, et al. Comparison of short-term results after laparoscopic complete mesocolic excision and standard colectomy for rightsided colon cancer: analysis of a Western center cohort. Ann Coloproctol 2021;37:166-73.

12. Lavy R, Madjar-Markovitz H, Hershkovitz Y, Sandbank J, Halevy A. Influence of colectomy type and resected specimen length on number of harvested lymph nodes. Int J Surg 2015;24(Pt A):91-4.

13. Neufeld D, Bugyev N, Grankin M, Gutman M, Klein E, Bernheim J, et al. Specimen length as a perioperative surrogate marker for adequate lymphadenectomy in colon cancer: the surgeon's role. Int Surg 2007;92:155-60.

14. Gelos M, Gelhaus J, Mehnert P, Bonhag G, Sand M, Philippou S, et al. Factors influencing lymph node harvest in colorectal surgery. Int J Colorectal Dis 2008;23:53-9.

15. Hsu TW, Lu HJ, Wei CK, Yin WY, Chang CM, Chiou WY, et al. Clinical and pathologic factors affecting lymph node yields in colorectal cancer. PLoS One 2013;8:e68526.

16. Altintas S, Bayrak M. Assessment of factors influencing lymph node count in colorectal cancer. J Coll Physicians Surg Pak 2019; 29:1173-8.

17. Orsenigo E, Gasparini G, Carlucci M. Clinicopathological factors influencing lymph node yield in colorectal cancer: a retrospective study. Gastroenterol Res Pract 2019;2019:5197914.

18. Brändstedt J, Wangefjord S, Nodin B, Gaber A, Manjer J, Jirström K. Gender, anthropometric factors and risk of colorectal cancer with particular reference to tumour location and TNM stage: a cohort study. Biol Sex Differ 2012;3:23.

19. Becerra AZ, Aquina CT, Berho M, Boscoe FP, Schymura MJ, Noyes K, et al. Surgeon-, pathologist-, and hospital-level variation in suboptimal lymph node examination after colectomy: compartmentalizing quality improvement strategies. Surgery 2017; 161:1299-306.

20. Hamza A, Sakhi R, Khawar S, Alrajjal A, Edens J, Khurram MS, et al. Role of "second look" lymph node search in harvesting optimal number of lymph nodes for staging of colorectal carcinoma. Gastroenterol Res Pract 2018;2018:1985031.

21. Nathan H, Shore AD, Anders RA, Wick EC, Gearhart SL, Pawlik TM. Variation in lymph node assessment after colon cancer resection: patient, surgeon, pathologist, or hospital? J Gastrointest Surg 2011;15:471-9.

22. Stracci F, Bianconi F, Leite S, Liso A, La Rosa F, Lancellotta V, et al. Linking surgical specimen length and examined lymph nodes in colorectal cancer patients. Eur J Surg Oncol 2016;42:260-5.

23. Üreyen O, Ulusoy C, Acar A, Sağlam F, Kızıloğlu İ, Alemdar A, et al. Should there be a specific length of the colon-rectum segment to be resected for an adequate number of lymph nodes in cases of colorectal cancers?: a retrospective multi-center study. Turk J Surg 2020;36:23-32. 